\title{
El azar en los romanos antes de las "escuelas morales"
}

En Roma se sucedieron, desde los tiempos de la República, diversas disposiciones prohibiendo los juegos de azar e imponiendo sanciones a los que tenían casas de juego u ofrecían un refugio a los jugadores. No obstante, hasta el mismo emperador jugaba a ellos siendo Augusto, Calígula, Claudio, Nerón, grandes jugadores. Claudio escribió un libro sobre el tema por lo que la prohibición fue poco respetada, jugándose grandes sumas en los festines y tabernas públicas.

Según Tácito ${ }^{1}$, los germanos, cuando nada les quedaba, jugaban su libertad y persona a los dados. Igualmente se relata de los hunos, jugándose el botín conquistado con las armas de la guerra, y que en su apasionamiento hasta se jugaban la vida.

La época romana no sólo fue una época de sed irrefrenable de sangre sino también de pesimismo y de desaliento en lo tocante a la capacidad del hombre para forjarse su propio futuro. La existencia del gobierno imperial con la propaganda que recababa para él el apoyo de los antiguos dioses, no lograba suprimir la arraigada creencia de que el hombre caminaba a la deriva, y todo en su vida era incierto. De ahí que la deidad del desaliento imperante fuera la Fortuna. "En todo el mundo - dice Plinio el Viejo-, en todo lugar, a toda hora, las voces de todos los hombres invocan tan sólo a la Fortuna; tan sólo a ella se acusa, tan sólo ella es culpable, tan sólo en ella se piensa. A nadie sino a ella se alaba, se discute, se rinde culto con denuestos. La tienen por voluble, y muchos, incluso, por ciega, errante, inconstante, cambiante, y favorecedora de los indignos" 2.

Plinio el Viejo (23-79) escribía en el siglo I, pero probablemente estaba bebiendo de fuentes griegas de muchos años atrás. En efecto, el culto a la

1. TACITO, C., De origine et situ germanorum, 24.

2. Plinio, C., Naturalis historiae, II, 22. 
Fortuna, según deja ver el griego Polibio (210-120) ${ }^{3}$, se había extendido victoriosamente por todo el mundo mediterráneo ya en los siglos III y II a. de C. Se contaban por millones la gente a quienes le parecía que todo era gobernado por el más puro azar.

"No hay dioses: decir que Júpiter reina es errado; es un ciego azar lo que se mueve a lo largo de los años" 4.

Muchos opinan que la suerte o Fortuna era un orden de cosas que quedaban allende la comprensión del hombre, pero no se había establecido una teoría sobre ella; las gentes la podían ver elevar o abatir a los hombres, tal como la veía Horacio (65-8).

"Fortuna, gozosa de su cruel actividad, obstinada en jugar a su juego caprichoso, traspasa sus favores inciertos conmigo hoy benévola, mañana con otro" 5 .

Una de las estatuas más famosas y de mayor influencia del mundo antiguo fue la Fortuna ( $\tau \gamma \gamma \eta$ ) de Eutíquides (296-290 a. de C.), de la ciudad esplendorosa de Antioquía, recién fundada, que a no tardar iba a convertirse, después de Roma y Alejandría, en la tercera gran ciudad del imperio romano. El escultor representa a la Fortuna sentada en el río Orontes a sus pies. Hubo innumerables copias de esta estatua, y cada comunidad tuvo su Fortuna propia. Cada hombre tenía a sí mismo la suya, y el término llegó a personificar casi su propia individualidad y el sesgo que tomaba su vida, interpretándose diversamente, bien como un don dispensado por una sabia providencia, bien como una fuerza enteramente caprichosa.

Los emperadores se anexionaron a la Fortuna, ostentando sus monedas; la "Fortuna de los Augustos", representación edificante de la elevación especial, la entrega a su cometido, y las fatigas de la vida tan importante del Príncipe.

En casas y palacios se custodiaban estatuillas privadas de la Fortuna; Antonino Pío tenía una de oro en su dormitorio y sus monedas se clasifican de "obsequens", es decir, de favorable a sus deseos.

Las monedas de Cómodo la muestran como "manens", como permanente y tan firmemente sujeta como el cordel que retiene ella con las riendas en varias representaciones. La creencia en la Fortuna se extendía a lo largo y a lo ancho más allá de las fronteras del mundo greco-romano y sobrevivió durante mucho tiempo a Roma. Dante la invocaba y en muchos países los

3. Polibio, Historia, II, 38, 5.

4. Polibro, Historia, adaptación de Juvenal en Sátira X, 365ss.

5. Horacio, Oda III, 29, 49s. 
hombres del Renacimiento mostraron la misma arrobada emoción devota a la Fortuna, representándola o simbolizándola en muchas pinturas.

En el siglo I a. de C. la gente empezó a hablar menos de la Fortuna y más del hado. Sus relaciones eran tan vagas y fluctuantes como lo son hoy en día cuando el vulgo habla de ellos, pues no siempre hay por necesidad gran diferencia entre "la suerte lo quiso así", que aparece con tanta regularidad en las noticias necrológicas.

Ambas concepciones implican una negación o al menos una restricción del valor de la conducta humana. Sin embargo era posible distinguir entre lo uno y lo otro si se quería. Horacio apostrofa a la Fortuna como si el Hado caminara delante de ella:

Delante de ti siempre va tu esclava, la Necesidad,

llevando en sus manos de bronce los clavos de carpintero y las cuñas, sin fallarle el duro garfio ni el líquido plomo" 6 .

Un filósofo del siglo II d. de C. señaló cuán ilógico era creer a la vez en la Fortuna y el Hado ${ }^{7}$. Sin embargo ciertas personas operaban con ciertas personificaciones o deidades situándolas en diferentes regiones del universo, creyendo que la Necesidad estaba por encima de la Luna y la Suerte y los malos demonios por debajo de ella. Otros aceptaban gustosos el Hado como escape a la ciega Fortuna.

En general, el Hado era más respetable; al menos era una causa "como un hilo sutil", según Zenón el fundador del estoicismo, que corre a través de la totalidad de la existencia ${ }^{8}$. Pero su rival Epicuro juzgó preferible estar esclavizado a los antiguos dioses del vulgo, por inútiles que fueran, a estarlo al Destino de los filósofos. Como Epicuro, muchos romanos se sintieron oprimidos por la tiranía del Destino, imposible de esquivar.

El poeta Manilio a comienzos del siglo I escribe: "Los Hados rigen la tierra y todas las cosas están establecidas por una ley fija... al nacer morimos, y nuestro fin depende de nuestro principio" 9 .

Aurelio Fusco, el maestro de Ovidio, dice: "desde el nacimiento está determinado el día de la muerte" ${ }^{10}$. Manilio y Fusco están expresando la creencia en el Hado inevitable e irremediable que hizo del estoicismo, a pesar de su creencia aparentemente contradictoria en Dios y en la ética, una doctrina terriblemente mecanicista.

6. Horacio, Oda I, 35, 17-21

7. Afrodisia, A., De anima mantissa, p. 182, 18 Bruns.

8. ZENON DE CiTIO según ARNIM en Stoicorum veterum fragmenta, 4 vols., Leipzig, Teubner 1903-1905; I Zenón y discípulos 87 (1905).

9. Manilio, 14.

10. Cita de SÉNeCA el Retor, en Suasorias, II, 2. 
Cicerón se había negado a creer en una fuerza ciega: "Llamamos Hado a la ordenación y a la serie de causas, según la cual la unión de una causa con otra produce un efecto". Y la Fortuna se "aduce para cubrir nuestra ignorancia de los acontecimientos y sus causas" ${ }^{11}$. Su punto de vista personal era decididamente humanístico. Aun admitiendo el papel efectivo y enorme que desempeñaba el ciego azar en los grandes acontecimientos, como son las victorias y las derrotas, no obstante en su interpretación de los mismos sostiene que, a pesar de este elemento de suerte, no pueden efectuarse ni para bien ni para mal sin la intervención de nuestros semejantes. Por consiguiente necesitamos de la cooperación de nuestros semejantes para cualquier acontecimiento siendo el azar un elemento secundario.

La mente profundamente religiosa de Virgilio tejió una compleja trama de creencias tradicionales y personales en torno a la figura del Hado. En la Eneida el término tiene significado y matices múltiples. Se puede referir al sino de los individuos y estos sinos pueden entrar en mutuo conflicto. El Hado virgiliano puede ser también el destino que guía la totalidad del universo; y en este sentido adquiere los atributos de la divina conducción del mundo estoico por el destino y se convierte en expresión de la divinidad inmanente al mundo.

El Hado y Júpiter son invocados separada, aunque conjuntamente, en el himno al Destino del estoico Cleante ${ }^{12}$, aunque ambos aparecen en el poema de Virgilio, no siempre queda en claro si el poeta opina que la voluntad de Júpiter está subordinada al Hado o se distingue de él. Pero en el fondo de su corazón Virgilio profesaba como los estoicos una creencia monoteística en una divinidad omnipotente sinónima del Hado, cuyo servicio no es ciertamente el cometido de una libertad perfecta, sino el correspondiente a la mayor de las virtudes, la pietas.

La pietas es la virtud más elevante del Pius Aeneas, que exclamaba: "Acudamos dó la divinidad y la dura Fortuna nos llama" 13. La Fortuna puede tener en la Eneida infinidad de significados, desde el Hado a su contrario - una protesta en favor del libero arbitrio personal- pero en su esencia el Hado o la Fortuna de Virgilio no es una mera fuerza mecánica que surja de las leyes de la naturaleza como la $\alpha v \alpha v \chi \eta$ griega, a un capricho sin sentido, como encontramos que es a veces en los poetas griegos, sino un propósito deliberado del ser divino que está por encima del mundo y en el mundo.

11. Cicerón, M.T., Academicae disputationes, I, 7, 30.

12. Cleantes de Assos, Himno a Zeus, según 528 ARnim en op. cit.

13. Virgilio, P., Aeneida, XII, 676; cita de la traducción directa del latín de Vicente López Soto, Edit. Juventud, Barcelona 1970, p. 283. 
Acontecimientos que parecen predestinados fatalmente y otros sucesos aparentemente contradictorios con todas las trazas de ser excepcionales dentro del esquema de la fatalidad, se deben unos y otros a la intervención de la Providencia, a la que ponen en relación con el universo algunos pasajes solemnes de las Geórgicas y de la Eneida donde se combina la fe más profunda y las explicaciones más elaboradas, profundamente meditadas y difíciles del universo. A pesar de que los romanos no eran una raza dotada para la filosofía, es sorprendente enterarse de que Virgilio, si hubiera vivido más tiempo, estaba decidido a consagrar su vida a la filosofía.

La respuesta de Tácito al dilema entre su Hado rector de todas las cosas y la libertad de la voluntad humana no es menos concienzuda, pero sí más atormentada, perpleja y en la última instancia, indecisa. Tácito es un fatalista pero tan sólo hace intervenir el Hado cuando no tiene a la mano otras causas. Su creencia en los fenómenos sobrenaturales es vacilante y espasmódica. En general tan vez se incline por el compromiso estoico en boga que permite creer que, a pesar de estar las circunstancias externas del hombre determinadas, su vida interior depende de su propia elección. El comentario de Tácito a las anécdotas relativas a los supuestos poderes proféticos de Trasilo, el astrólogo de la corte de Tiberio, es característico y revelador:

"Cuando oigo contar estas y otras cosas parecidas me entran dudas de si los asuntos de los mortales se desarrollan según la necesidad inmutable del Hado o según el azar.

"En efecto, a los hombres más sabios de antaño, y a los que siguen sus doctrinas se les encuentra de pareceres opuestos. Muchos tienen arraigada la opinión de que ni nuestros nacimientos ni nuestras muertes, ni en una palabra, los hombres les importan nada a los dioses; y así con harta frecuencia las cosas tristes recaen sobre los buenos, y las alegres en los malos. Por el contrario, otros consideran que, si es verdad que las cosas suceden de acuerdo con el Hado, no es ello debido al curso de las estrellas, sino a los principios y conexiones de las causas naturales. Con todo, nos dejan la facultad de elegir nuestra propia vida, pero una vez elegida sostienen que el orden de los acontecimientos futuros está ya determinado. Pero, sin embargo, no son malas o buenas las cosas que por tales tiene el vulgo: muchos que parecen abrumados por las adversidades son felices; y otros muchos, aụn pasando la vida en gran abundancia, desgraciadísimos, si los primeros soportan el rigor de su fortuna sin desfallecimiento y los últimos hacen un uso inconsiderado de su prosperidad.

"Por lo demás, a la mayor parte de los hombres no se les quita de la cabeza que el futuro está predestinado desde el nacimiento, y que si algunas cosas resultan al revés de lo predicho, se debe a la impostura de quienes pre- 
dican lo que ignoran; y que así se destruye la fe en un arte del que han dado notables testimonios los tiempos antiguos y el nuestro... De ahí que me vea obligado a dudar de que el favor se daba al Hado sino que depende en algo de nuestras determinaciones" 14 .

Más avanzado el siglo II d. de C. en que escribía Tácito estos y otros problemas análogos, fueron sometidos a un examen crítico, frío y burlón por uno de los escépticos más populares y divertidos, el escritor griego o grecosirio Luciano de Samosata del Eufrates. La finalidad de sus ficciones, ingeniosas y paradójicas era nihilista: el no tener ni esperanzas ni temores y reirse de las locuras y pretensiones de los demás. Empleando con viveza la forma del diálogo en sus ensayos, narraciones cortas, mimos y parodias, presenta en uno de sus "Diálogos de los muertos" a Minos, el juez supremo, acorralado por las lógicas objeciones sobre el Hado que suscita un pirata recientemente fallecido, Sóstrato.

Esta firme creencia en un hado inamovible o difícilmente modificable o en una suerte ciega, originó la convención de la inutiliạad de todo esfuerzo y el tedio, que Séneca describe como característico de su época ${ }^{15}$. Pero el pueblo reaccionó ante unas perspectivas sin esperanza retornando a un cúmulo pintoresco de supersticiones diversas, más omenos sensacionales.

Vemos, pues, que la gran mayoría de la población del Imperio romano, inclusive un número crecido de las gentes más educadas, creía en las estrellas, recibiendo de esta creencia un gran impulso su aceptación del Hado o la Fortuna. Es decir, creían que los movimientos del sol, la luna y las estrellas, ejercen influencia en la vida, muerte, venturas y desventuras de la humanidad.

A. E. MASDIAS QUINTELA
Doctor en Filosofía

La Coruña

14. TÁCITO, C., Annales IV, 20, 3 y VI, 22.

15. SÉneCA, L.A., Ad Serenum de Tranquillitate animi, 2, resumen de la traducción directa del latín de Pedro Fernández Navarrete de SÉNECA, Tratados morales, Espasa Calpe, Buenos Aires 1943, pp. 66-70. 